\title{
Electroacoustic Polymer Microchip as an Alternative to Quartz Crystal Microbalance for Biosensor Development
}

\author{
Jean Gamby, ${ }^{*},{ }^{\dagger}$ Mathieu Lazerges, ${ }^{\dagger}$ Hubert H. Girault, ${ }^{\star}$ Claude Deslouis, ${ }^{\dagger}$ Claude Gabrielli, ${ }^{\dagger}$ \\ Hubert Perrot, ${ }^{\dagger}$ and Bernard Tribollet ${ }^{\dagger}$
}

Laboratoire Interfaces et Systèmes Electrochimiques, CNRS UPR15-LISE, Université Pierre et Marie Curie, 4 Place Jussieu, Paris, F-75005 France, and Laboratoire d'Electrochimie Physique et Analytique, Faculté des Sciences de Base, Institut des Sciences et Ingénierie Chimiques, Ecole Polytechnique Fédérale de Lausanne, 1015 Lausanne, Switzerland

Laser photoablation of poly(ethylene terephthalate) (PET), a flexible dielectric organic polymer, was used to design an acoustic miniaturized DNA biosensor. The microchip device includes a $100-\mu \mathrm{m}$-thick PET layer, with two microband electrodes patterned in photoablated microchannels on one side and a depressed photoablated disk decorated by gold sputtered layer on the other side. Upon application of an electric signal between the two electrodes, an electroacoustic resonance phenomenon at $\sim 30$ MHz was established through the microelectrodes/PET/ gold layer interface. The electroacoustic resonance response was fitted with a series $R L C$ motional arm in parallel with a static $C_{0}$ arm of a Buttlerworth-Van Dyke equivalent circuit: admittance spectra recorded after successive cycles of DNA hybridization on the gold surface showed reproducible changes on $R, L$, and $C$ parameters. The same hybridizations runs were performed concomitantly on a $27-\mathrm{MHz}(9 \mathrm{MHz}$, third overtone) quartz crystal microbalance in order to validate the PET device developed for bioanalysis applications. The electroacoustic PET device, $\sim 100$ times smaller than a microbalance quartz crystal, is interesting for the large-scale integration of acoustic sensors in biochips.

Poly (ethylene terephthalate) (PET) (Chart 1) is one of the most widely used thermoplastic polymers, ${ }^{1}$ with many applications in everyday life encompassing different manufactured objects such as bottles, clothes, wire coatings, and electrical switches. Because PET is constituted of a main polymer chain having active primary $(\alpha)$ and secondary $(\beta)$ dielectrically relaxation processes, ${ }^{2-7}$ it has attracted much interest for fundamental investigations by dielectric relaxation spectroscopy, ${ }^{6}$ a thermally stimulated discharge

* To whom correspondence should be addressed. Tel: +3314427 2125. Fax: +33 14427 4074. E-mail: jean.gamby@upmc.fr.

${ }^{\dagger}$ Université Pierre et Marie Curie.

* Ecole Polytechnique Fédérale de Lausanne.

(1) Seymour, R. B. Popular Plast. Packag. 1989, 34 (10), 57-58.

(2) (a) Boyd, R. H. Polymer 1985, 26, 323-347. (b) Corburn, J. C.; Boyd, R. H. Macromolecules 1986, 19, 2238-2245.

(3) Tatsumi, T.; Ito, E.; Hayakawa, R. I. Polym. Sci., Part B. Polym. Phys. 1992, 30, 701-705.

(4) Dargent, E.; Santais, J. J.; Saiter, J. M.; Bayard, J.; Grenet, J. I. Non-Cryst. Solids 1994, 172, 1062-1065.

\section{Chart 1. Polyethylene Terephthalate (PET)}

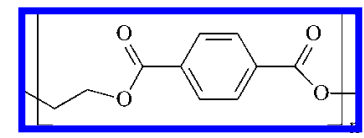

current, ${ }^{6 b, 8-10}$ and finalisothermal discharging currenttechniques ${ }^{11 a-c}$ to analyze charge transport and trapping in highly insulating materials. The study of dielectric response of polymeric systems is an excellent diagnostic tool since it reflects the molecular structure, dipole motions and their mutual influence inside semicrystalline or amorphous materials.

As a transparent material, PET has also found applications for the design of biosensors as a support material for biomolecules. Also, its surface properties can be easily tailored by physical or chemical means, which is useful for patterning purposes. ${ }^{12}$ From a biosensor manufacturing viewpoint, laser photoablation is a method that enables production of microfluidic chips used in chromatographic separation coupled to mass spectrometry. ${ }^{13-15}$ Photoablated PET presents on its surface ionisable groups, ${ }^{16 \mathrm{c}}$ which can be used to generate electroosmotic flows when they

(5) Kusabiraki, M.; Aozasa, M. Thin Solid Films 1996, 281, 533-535.

(6) (a) Neagu, E. R.; Pissis, P.; Apekis, L.; Gomez Ribelles, J. L. J. Phys. D: Appl. Phys. 1997, 30, 1551-1560. (b) Neagu, R. M.; Neagu, E. R.; Kalogeras, I. M.; Vassilikou-Dova, A. Mater. Res. Innovations 2001, 4, 115-125.

(7) Job, A. E.; Alves, N.; Zanin, M.; Ueki, M.; Mattoso, L.; Teruja, M.; Giacometti, J. A. J. Phys. D: Appl. Phys. 2003, 36, 1414.

(8) Bucci, C.; Fieshi, R.; Guidi, G. Phys. Rev. 1966, 148, 816-823.

(9) Chen, R. J. Electrostat. 1977, 3 (1-2-3), 15-24.

(10) Teyssedre, G.; Demont, P.; Lacabanne, C. L. Appl. Phys. 1996, 79, 9258.

(11) (a) Neagu, E. R.; Marat-Mendes, J. N. I. Appl. Phys. Part 2 2001, 40, L1160. (b) Lança, M. C.; Neagu, E. R.; Marat-Mendes, J. N. L. Phıs. D: Appl. Phvs. 2002, 35, L29-L32. (c) Neagu, E. R.; Marat-Mendes, J. N. Appl. Phys. Lett. 2002, 82, 2488.

(12) Schwarz, A.; Rossier, J. S.; Roulet, E.; Mermod, N.; Roberts, M. A.; Girault, H. H. Langmuir 1998, 14, 5526-5531.

(13) Rossier, J. S.; Reymond, F.; Michel, P. E. Electrophoresis 2002, 23 (6), $858-867$.

(14) Greiner, M.; Carter, P.; Korn, B.; Zink, D. Nat. Methods 2004, 1 (1), 8789.

(15) Brennen, R. A.; Yin, H.; Killeen, K. P. Anal. Chem. 2007, 79 (24), 93029309.

(16) (a) Roberts, M. A.; Rossier, J. S.; Bercier, P.; Girault, H. H. Anal. Chem. 1997, 69, 2035-2042. (b) Rossier, J. S.; Schwarz, A.; Reymond, F.; Ferrigno, R.; Bianchi, F.; Girault, H. H. Electrophoresis 1999, 20 (4-5), 727-731. (c) Bianchi, F.; Chevolot, Y.; Mathieu, H. J.; Girault, H. H. Anal. Chem. 2001, 73 (16), 3845-3853. (d) Bianchi, F.; Lee, H. J.; Girault, H. H. J. Electroanal. Chem. 2002, 523 (1-2), 40-48. Published on Web 11/01/2008 


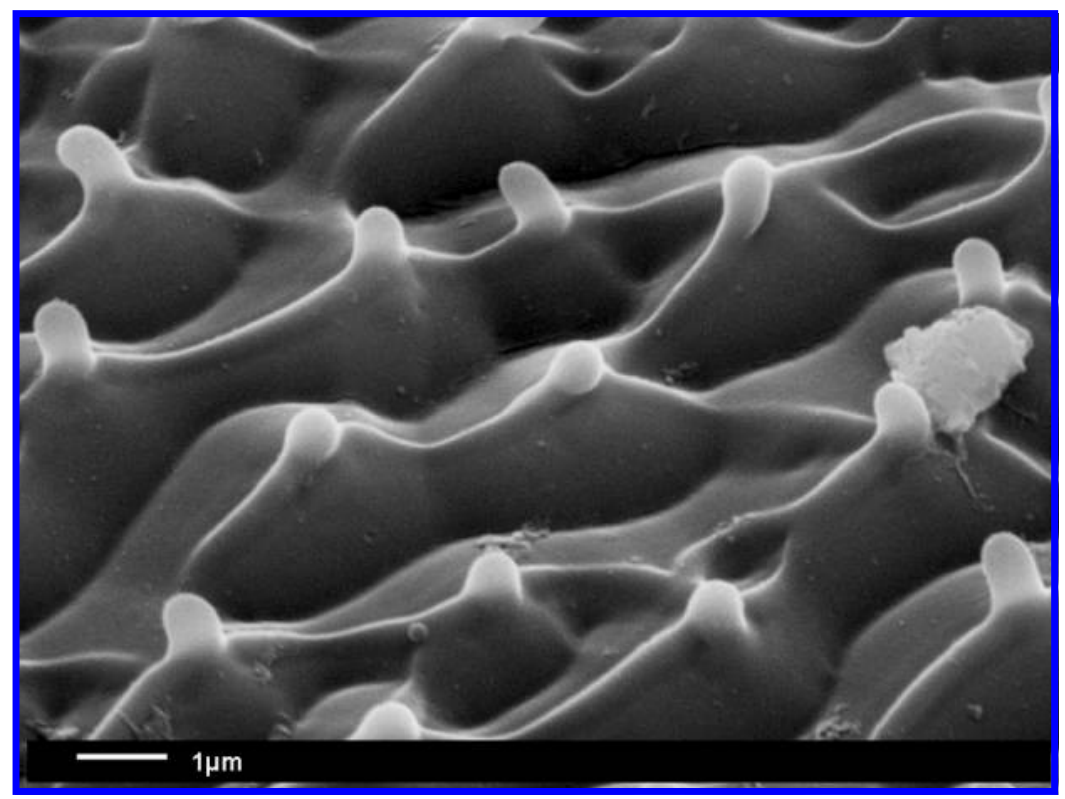

Figure 1. Aspect of semicrystalline PET after laser photoablation at $250 \mathrm{~mJ} \mathrm{~cm}^{-2}$.

are in contact with a solution ${ }^{16 a}$ and therefore presents interesting potentialities for designing microfluidic chips. ${ }^{16}$

Different methods have been proposed for the detection of adsorbed molecules on PET. For example, laser-induced fluorescence confocal microscopy was optimized ${ }^{17,18}$ to investigate the adsorption of a fluorescently labeled antigen (immunoglobulin G) on PET microchannels. In another domain, supercapacitive admittance tomoscopy was developed to study the capacitive coupling across a thin PET layer separating microband electrodes from the solution. ${ }^{19}$ Adsorption of charged biomolecules of a flowing solution on the surface of a PET-modified microchannel induces device capacitance changes. Hence, depending on the amplitude of the capacitance variation, the concentration of biomolecules can be determined.

Recently, ultrasonic transducer and made of highly piezoelectric elastic PET films using a thickness extension resonance ${ }^{20}$ at $120-150 \mathrm{kHz}$ frequencies were reported as promising devices. This advanced technology requires a physical foaming treatment of PET in supercritical $\mathrm{CO}_{2}$ at high pressure followed by a heat treatment (above the glass transition temperature $T_{\mathrm{g}}$ ) in order to stabilize the structural changes. ${ }^{20 a}$ The final treatment was achieved by application of a high voltage to induce dipolar polarization in the internal voids of the PET film, which can be used as ferroelectric or in electroacoustical transducer. ${ }^{20 \mathrm{c}} \mathrm{How}-$ ever, except when chemical and physical treatments are carried

(17) Wu, Z.; Jensen, H.; Gamby, J.; Bai, X.; Girault, H. H. Lab Chip 2004, 4 (5), $512-515$.

(18) Shadpour, H.; Musyimi, H.; Chen, J.; Soper, S. A. L. Chromatogr., A 2006, 1111 (2), 238-251.

(19) (a) Gamby, J.; Abid, J.-P.; Girault, H. H. I. Am. Chem. Soc. 2005, 127, 13300-13304. (b) Gamby, J.; Abid, J.-P.; Abid, M.; Ansermet, J.-P.; Girault, H. H. Anal. Chem. 2006, 78, 5289-5295. (c) Gamby, J.; Lazerges, M.; Pernelle, C.; Perrot, H.; Girault, H. H.; Tribollet, B. Lab Chip 2007, 7, 16071609. (d) Gamby, J.; Abid, J.-P.; Tribollet, B.; Girault, H. H. Small 2008, 4 (6), 802-809.

(20) (a) Wirges, W.; Wegener, M.; Voronina, O.; Zirkel, L.; Gerhardt-Multhaupt, R. Adv. Funct. Mater. 2007, 17, 324-329. (b) Fang, P.; Wegener, M.; Wirges, W.; Gerhard, R.; Zirkel, L. Appl. Phys. Lett. 2007, 90, 192908. (c) Fang, P.; Wirges, W.; Wegener, M.; Zirkel, L.; Gerhard, R. e-Polymer 2008, $43,1-9$. out to turn PET into a piezoelectric active film, it is not possible to use raw PET in such devices.

Nevertheless, on close inspection, some important aspects about the photoablation treatment of PET have to be taken into account due to its unusual thermodynamic conditions (high temperature, high pressure). It is reasonable to think that such a treatment has important consequences on the properties of the photoablated polymer as mentioned previously. Several authors ${ }^{21-27}$ have studied the photoablation process on polymer materials at different fluences for amorphous and semicrystalline samples with an accepted value for melting the polymer surface around $80 \mathrm{~mJ}$ $\mathrm{cm}^{-2}$ (ArF, 193-nm laser). ${ }^{21 \mathrm{a}, \mathrm{b}}$ The most suggested phenomenon is described as a photochemical process coupled with photothermal degradation. ${ }^{21 c, 24,25}$ The challenge is to understand clearly the working mechanism of such treatment related to the imposed unusual thermodynamic conditions, such as high temperature $\left(\sim 900^{\circ} \mathrm{C}\right)$ and high pressure (a few hundred bars), created by the laser that lead to the formation of new phases on the polymer substrate. ${ }^{21 f}$ Indeed, in the case of PET, Watanabe et al..$^{24}$ have proposed a resulting structure that consists of an ablation layer, a fusion layer, and a layer heated above the glass transition temperature. For each layer, the thickness increased with the increase of the irradiation energy with threshold fluence of the

(21) (a) Novis, Y.; Pireaux, J. J.; Brezini, A.; Petit, E.; Caudano, R.; Lutgen, P.; Feyder, G.; Lazare, S. L. Appl. Phys. 1988, 64 (1), 365-369. (b) Lazare, S.; Granier, V. L. Appl. Phys. 1988, 63 (6), 2110-2115. (c) Lazare, S.; Granier, V. Laser Chem. 1989, 10, 25-40. (d) Bolle, M.; Lazare, S.; Le Blanc, M.; Wilmes, A. Appl. Phys. Lett. 1992, 60 (6), 674-676. (e) Lazare, S.; Lopez, J.; Weisbuch, F. Appl. Phys. A: Mater. Sci. Process. 1999, 69, S1-S6. (f) Weisbuch, F.; Tokarev, V. N.; Lazare, S.; Débarre, D. Appl. Phys. A: Mater. Sci. Process. 2003, 76, 613-620.

(22) Dyer, P. E.; Jenkins, S. D.; Sidhu, J. Appl. Phys. Lett. 1986, 49 (8), 453455.

(23) Dunn, D. S.; Ouderkirk, A. J. Macromolecules 1990, 23, 770-774.

(24) Watanabe, H.; Yamamoto, M. J. Appl. Polym. Sci. 1997, 64, 1203-1209.

(25) Krajnovich, D. J. L. Appl. Phys. 1997, 82 (1), 427-435.

(26) Rossier, J. S.; Bercier, P.; Schwarz, A.; Loridant, S.; Girault, H. H. Langmuir 1999, 15, 5173-5178.

(27) Fardel, R.; Nagel, M.; Lippert, T.; Nuesch, F.; Wokaun, A.; Luk'Yanchuk, B. S. Appl. Phys. A: Mater. Sci. Process. 2008, 90, 661-667. 
laser excimer. Figure 1 illustrates the result obtained on a sample of semicrystalline PET after photoablation using a $193 \mathrm{~nm}$ laser at $250 \mathrm{~mJ} \mathrm{~cm}^{-2}$. A surface roughness appears in the photoablated area, displaying regular valleys and hills in a micrometer scale. Lazare et al. ${ }^{21 a, f}$ have investigated the surface properties of two photoablated polyesters, poly(ethylene naphthalate) and PET, using a plethora of different techniques like atomic force microscopy, scanning electron microscopy (SEM), transmission electron microscopy, ellipsometry, and quartz crystal microbalance (QCM), in order to enlighten the origin of such a relief on the surface. The most interesting result in their work, which can help to interpret Figure 1, is the enlightenment on the mechanism of formation of the regular bumps at the top of each hill resulting from the solidification of a viscous liquid flow constituted by a mixture of ablation products (monomers and gases). Nevertheless, the authors have noted that, for two samples which are ablated with a micropatterned single pulse of $\mathrm{KrF}$ laser, bumps appear only on a PET (semicrystalline, 60\%) and not on PET (amorphous, $100 \%){ }^{21 f}$ They have correlated this absence of bumps on amorphous PET to its much lower density than for the crystalline PET, which facilitates a better mix between the heated amorphous PET layer with the viscous liquid flow of supercritical media or superheated states. In addition, crystallinity measurements with spectroscopy ( $\mu$-confocal Raman) confirm the slight changes in surface crystallinity, and Raman imaging shows a more homogeneous surface, after laser photoablation. ${ }^{26}$ In other words, bumps can be seen as nanocrystalline particles that induce these modifications on the surface properties. Therefore, photoablation induces changes in the PET that can be considered as similar to those imposed by the treatments inducing piezoelectricity reported in the literature.

Until now, schemes of QCM miniaturization were limited from a technological point of view because microsized crystals are extremely brittle and hard to integrate in microchips. Hence, a strategy to design miniaturized electroacoustic DNA biosensors using flexible photoablated PET is reported in this work. The resonator consists of two microelectrodes embedded in a PET thin film covered with a gold layer. The electroacoustic admittance response of the device around the resonance was measured with a network analyzer in order to monitor interfacial reaction in the vicinity of the gold layer in contact with the liquid media. The performances of this acoustic microchip, for analytical biochemistry applications, were evaluated in the case of DNA detection and compared to DNA detection based on classical QCM.

\section{EXPERIMENTAL SECTION}

Chemicals. $\mathrm{MgCl}_{2}$ and $\mathrm{NaCl}$ were from Sigma Aldrich (biochemical grade); 20-base 5 'thiol- $\mathrm{C}_{6}$-DNA probe and complementary 40-base DNA target were from Eurogentec (oligold quality); and water was double-distilled and deionized. The DNA probe is the complementary strand of a gene sequence encoding for a large rRNA subunit of Alexandrium minutum DNA, a microalgae that produces neurotoxins responsible for paralytic shellfish poisoning on European ${ }^{28}$ and Asian ${ }^{29}$ coasts.

(28) Bravo, I.; Vila, M.; Masó, M.; Figueroa, R. I.; Ramilo, I. Harmful Algae. In press.

(29) Lim, P.-T.; Sato, S.; Thuoc, C. V.; Tu, P. T.; Huyen, N. T. M.; Takata, Y.; Yoshida, M.; Kobiyama; Koike, A. K.; Ogata, T. Harmful Algae 2007, 6, 321-331.
Quartz Crystal Microbalance. The resonator of the microbalance was an AT-cut planar piezoelectric quartz crystal, $14 \mathrm{~mm}$ in diameter and $180 \mu \mathrm{m}$ thick, with a 9-MHz nominal resonance frequency (Matel-Fordhal). Two identical gold electrodes, 2000 $\AA$ thick and $5 \mathrm{~mm}$ in diameter, were deposited by evaporation techniques on both sides of the quartz crystal with a $250-\AA$ chromium underlayer. The resonator was connected by a silver conducting paste to wires. The quartz crystal was mounted between two O-ring seals inserted in a homemade plexiglass cell with a $50-\mu \mathrm{L}$ volume. Only one gold-coated face of the quartz crystal was in contact with the cell solution. The apparatus included a micropump (Pharmacia) to ensure a $50 \mu \mathrm{L} \min ^{-1}$ constant flow of the solutions in the quartz cell. A laboratory-made oscillator was designed to drive the quartz at $27 \mathrm{MHz}$, which corresponds to the third resonator overtone. To improve the stability, all the oscillator system was temperature-controlled thanks to a heater monitor (Watlow) with temperature stability better than $0.1{ }^{\circ} \mathrm{C}$. The frequency was monitored by a laboratorymade software (C language) and measured with a frequency counter (PM 6685 Philips).

Admittance Measurements for PET Microchip. The experimental setup was built by coupling the microchip to a network analyzer (HP 4194A) to apply the frequency and record the electrical admittance of this device. During the DNA hybridization, the frequency of the PET microchip and its admittance were sequentially measured by using an electronic switch. All the experimental setup was computer-controlled through a laboratorymade software (HP-VEE language). The electrical admittance measurements were performed automatically with a $10-\mathrm{mVpp}$ perturbation signal.

Microelectrodes and PET Photoablation. A PET $100-\mu \mathrm{m}-$ thick sheet $\left(\right.$ Melinex $\left.^{30}\right)$ was photoablated ${ }^{16 a}$ using a 193-nm argonfluor excimer laser (Lambda Physik LPX 2051) in order to obtain a depressed disk with a depth of $10 \mu \mathrm{m}$ and a diameter of $2 \mathrm{~mm}$ (Scheme 1a and b). The repetition rate of the laser pulses is varied from 1 to $50 \mathrm{~Hz}$ with a fluence per pulse at $250 \mathrm{~mJ} \mathrm{~cm}^{-2}$ under high-power conditions ( $40 \mathrm{MW}$ ). After photoablation, the debris produced by the laser ablation process was removed by rinsing with 2-propanol. On the other side of the PET film, two parallel microchannels with a depth of $50 \mu \mathrm{m}$ and a width of $100 \mu \mathrm{m}$ were photoablated perpendicularly to the surface (Scheme 1c and d). The separation between these two parallel microchannels was equal to $100 \mu \mathrm{m}$. The two channels were then filled with a commercial silver paste (Electra $\Omega$ ED3000 Electra Polymers). Another film of PET was laminated on the face of the PET film including the two $\mathrm{Ag}$ electrodes, by heating at $60{ }^{\circ} \mathrm{C}$ for $4 \mathrm{~h}$ (Scheme 1). A thin Au layer of $15 \mathrm{~nm}$ was deposited by dc plasma sputtering on the PET disk in order to graft thiol-labeled DNA probes (Scheme 1c). The microelectrodes were connected by a silver conducting paste to wires. The microchip was mounted between two O-ring seals inserted in a laboratory-made plexiglass cell. Only the gold-coated face was in contact with the cell solution.

\section{RESULTS}

DNA Hybridization Investigated with a QCM. A QCM DNA biosensor was designed as a reference system to compare the performances of the PET microchip presented in this article.

(30) MacDonald, W. A. J. Mater. Chem. 2004, 14, 4-10. 
Scheme 1. (a) Top View SEM Micrograph of a Photoablated Sheet PET Disk (Zone 2), Nonphotoablated Part (Zone 1). (b) Cross-Sectional Section View of the 10- $\mu \mathrm{m}$-Thick PET Disk. (c) Top View of the Device, PET Disk Coated with a 15-nm Gold Layer (Zone 3). (d) Cross-Sectional View of the Device: Trapezoidal Band Electrode Cross Section in Black (Zone 4) in Contactless Configuration (Zone 5) with the Gold Layer Deposited by Sputtering (Zone 3)

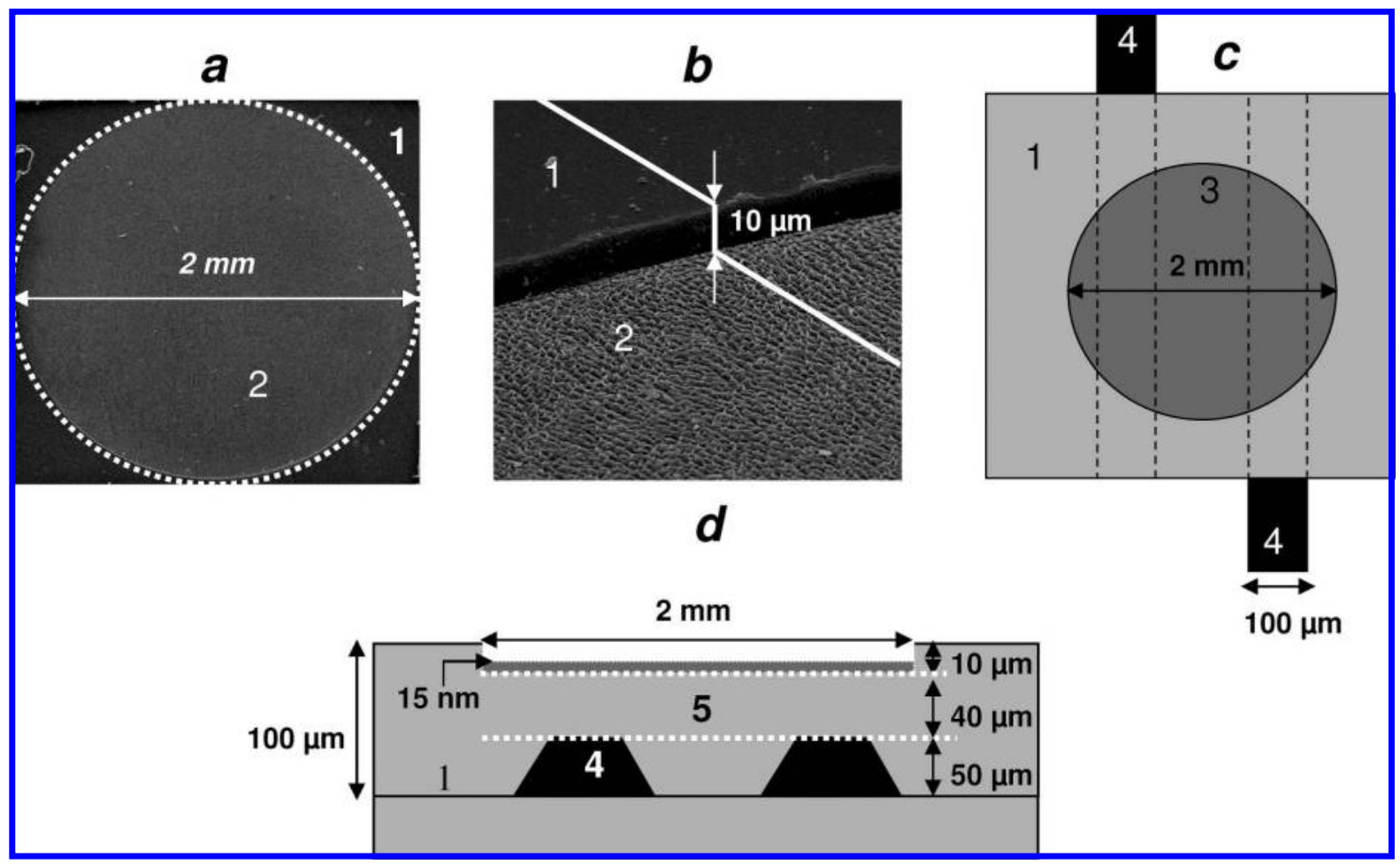

Scheme 2. DNA Immobilization and Hybridization on the Gold-Covered Quartz Surface

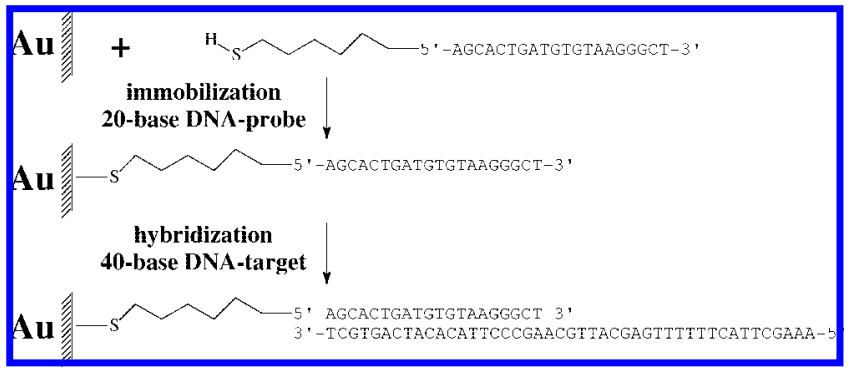

Scheme 2 describes the immobilization of a probe on the transducer surface followed by the hybridization of a DNA-target. A $260-\mathrm{Hz}$ frequency drop $\Delta f_{\text {probe }}$ was observed during the immobilization of the DNA-probe at $1.7 \mu \mathrm{M}$ in $0.5 \mathrm{M} \mathrm{NaCl}$ and a $230-\mathrm{Hz}$ frequency decrease $\Delta f_{\text {target }}$ during hybridization of the DNA-target at $1.7 \mu \mathrm{M}$ in $10^{-2} \mathrm{M} \mathrm{MgCl}_{2}$ (Figure 2). The hybridization ratio of number of DNA hybridized target $n_{\text {target }}$ versus DNA immobilized probe $n_{\text {probe }}$ is given by

$$
\tau=\frac{n_{\text {target }}}{n_{\text {probe }}}=\frac{\Delta f_{\text {target }} M_{\text {probe }}}{\Delta f_{\text {probe }} M_{\text {target }}}
$$

where $M_{\text {probe }}$ is the molecular weight of the 20-base disulfide-DNA probe $\left(6.10^{3} \mathrm{~g} \mathrm{~mol}^{-1}\right)$ and $M_{\text {target }}$ the molecular weight of the complementary 40-base DNA-target $\left(12.10^{3} \mathrm{~g} \mathrm{~mol}^{-1}\right)$. The $\tau$ value experimentally found from eq 1 was $44 \%$, which was consistent with previous results on the same biosensor, close to $40 \%{ }^{31-33}$
The same immobilization and hybridization runs were performed on the PET microchip.

Resonance in the PET Microchip. To validate our hypothesis about the possibility of PET piezoelectricity induced by photoablation, the electroacoustic response of the device was first tested. The electroacoustic response of the device was studied upon application of a $10 \mathrm{mVpp}$ perturbation in a frequency range from 2 to $50 \mathrm{MHz}$. Electroacoustic admittance modulus and phase curves (Figure 3a) present three resonance phenomena, at 11.2, 22.4 , and $29.6 \mathrm{MHz}$. These three resonance waves correspond to propagation of mechanical vibration in PET. The resonance at 22.4 $\mathrm{MHz}$ is attributed to the first harmonic of the fundamental resonance at 11.2 MHz. The electroacoustic admittance around this resonance at $30 \mathrm{MHz}$ will be used to monitor interfacial reactions in liquid media in the vicinity of the gold layer in order to design a DNA-biosensor.

DNA Hybridization Investigated with the PET Microchip. The characteristics of a damped quartz crystal ${ }^{34-36}$ (Scheme 3a) can be represented by a Buttlerworth-Van Dyke (BVD) ${ }^{37}$ electrical equivalent circuit consisting in a $R L C$ motional arm in parallel with a $C_{0}$ static capacitance (Scheme $3 \mathrm{c}$ ).

The electroacoustic resonance response of the PET device was well fitted with this BVD equivalent circuit. Figure 4 displays the admittance modulus spectra where the frequency span covers the complete resonant region, from which the circuit components were evaluated. The complex admittance $Y$ of the polymer

(31) Bizet, K.; Gabrielli, C.; Perrot, H. Appl. Biochem. Biotechnol. 2000, 89, 139-150.

(32) Zhou, C. X.; Huang, L. Q.; Li, S. F. Y. Biosens. Bioelectron. 2001, 16, 8595 . 


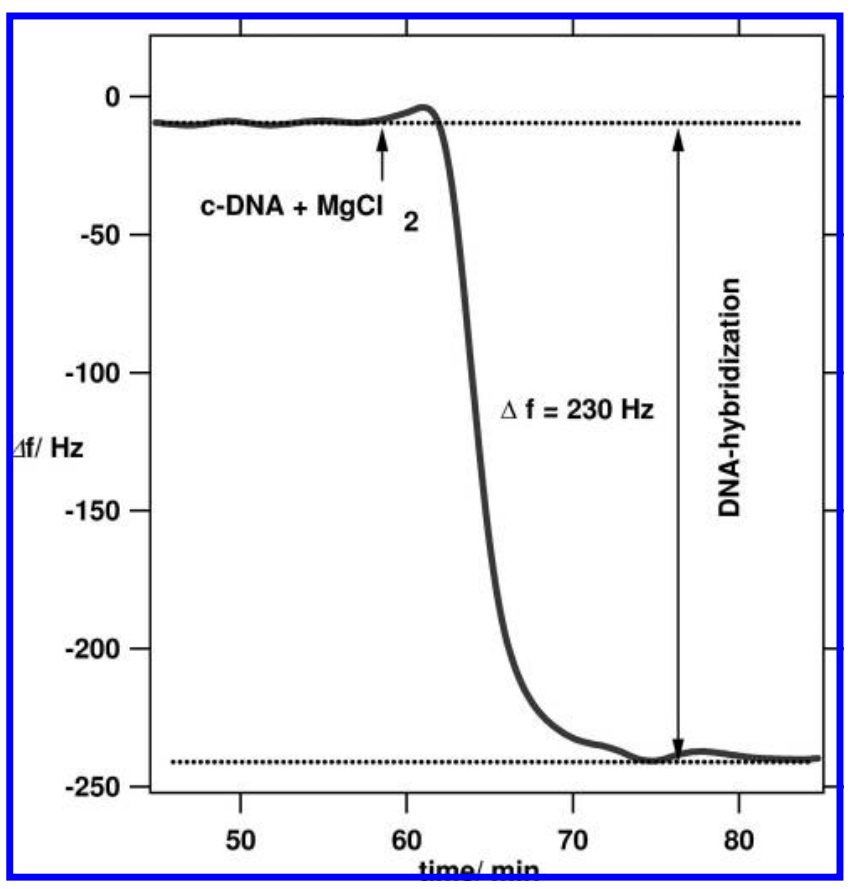

Figure 2. Microbalance frequency change during the circulation of a DNA-target solution at $10 \mu \mathrm{g} \mathrm{mL}^{-1}$ in $10^{-2} \mathrm{M} \mathrm{MgCl}_{2}$ aqueous solution.

microstructure is defined as, $Y=G+\mathrm{j} B$, where the conductance, $G$, is the real part of $Y$ and the susceptance, $B$, is the imaginary part of $Y$. The corresponding relations are deduced from the equivalent circuit of Scheme 3c:

$$
\begin{gathered}
Y(\omega)=\mathrm{j} \omega C_{0}+\frac{1}{R+\mathrm{j} \omega L+\frac{1}{\mathrm{j} \omega C}} \\
|Y|=\sqrt{G^{2}+B^{2}} \\
\tan \Theta=\frac{B}{G}
\end{gathered}
$$

when $\omega$ is the angular frequency $\left(\mathrm{rad} \mathrm{s}^{-1}\right)$, defined by $\omega=2 \pi f$, where $f$ is the frequency $(\mathrm{Hz})$ and $\Theta$ the phase angle related to $G$ and $B$ according to eq 4 . The values of the equivalent circuit components were determined through a fitting procedure based on a simplex algorithm. According to eq 2 , four parameters, $R, L$, $C$, and $C_{0}$ can be obtained by fitting the admittance expression given by $Y(\omega)$ to the corresponding experimental data $Y_{\exp }(\omega)$. The values of the parameters that correspond to the best fit are given after the minimization of the quadratic function $\Sigma(Y(\omega)-$ $\left.Y_{\exp }(\omega)\right)^{2}$ with a simplex algorithm.

Electroacoustic admittance spectroscopy with an ac voltage of $10 \mathrm{mVpp}$ was performed to understand the processes involved in this detection approach. The 20-base DNA thiol-labeled monolayer

(33) (a) Lazerges, M.; Perrot, H.; Niriniony, R.; Antoine, E.; Compere, C. Chem. Commun. 2005, 48, 6020-6022. (b) Lazerges, M.; Perrot, H. R.; Antoine, E.; Defontaine, A.; Compere, C. Biosens. Bioelectron. 2006, 21, 1355-1358.

(34) Matthys, R. J. Crystal oscillator circuits; John Wiley \& Sons: New York, 1983.

(35) Granstaff, V. E.; Martin, S. J. L. Appl. Phys. 1994, 75, 1319-1328.

(36) Zhou, T.; Nie, L.; Yao, S. J. Electroanal. Chem. 1990, 293, 1-18.

(37) Bandey, H. L.; Martin, S. J.; Cernosek, R. W.; Hillman, A. R. Anal. Chem. 1999, 71, 2205-2214.

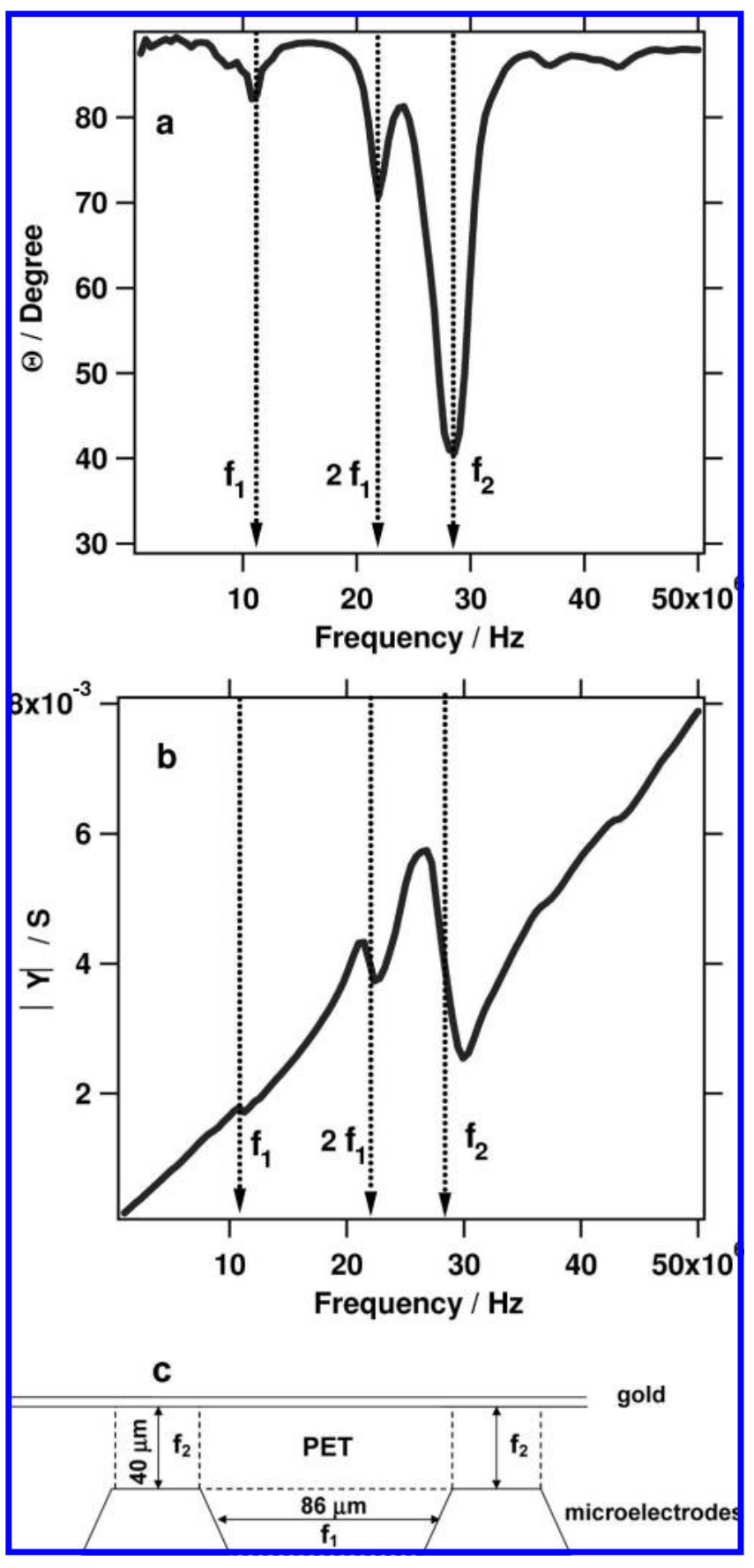

Figure 3. (a) Electroacoustic admittance phase curve of the PET device, (b) electroacoustic admittance modulus curve of the PET device, and (c) localization of the longitudinal vibrations corresponding to the fundamental resonances at $f_{1}=11.2 \mathrm{MHz}$ and $f_{2}=29.6 \mathrm{MHz}$.

was grafted on the PET gold disk by filling the PET device cell with a $10 \mu \mathrm{g} \mathrm{mL}^{-1}$ thiol-DNA solution in $0.5 \mathrm{M} \mathrm{NaCl}$ for $1 \mathrm{~h}$. The gold chemically modified surface was then rinsed three times with double-distillated water. Admittance measurements were performed on the device with a droplet of a $10^{-2} \mathrm{M} \mathrm{MgCl}_{2}$ hybridization buffer solution. $G$ real, $B$ imaginary, and $|Y|$ modulus parts of the admittance and corresponding Bode and Nyquist plots (Figure 4) are well fitted with a BVD model. Theoretical fit using eqs 3 and 4 yields to the parameters values: $L=7.9 \times 10^{-5} \mathrm{H}, C$ $=3.7 \times 10^{-13} \mathrm{~F}, R=1.45 \times 10^{3} \Omega$, and $C_{0}=2 \times 10^{-11} \mathrm{~F}$. Parameters $R, L$, and $C$ represent the motional arm and are 


\section{Scheme 3. (a) Representation of a Piezoelectric Quartz Crystal Sandwiched between Two Gold Electrodes. (b) Representation of a Electroacoutic PET with Two Insulated Silver Microband Electrodes. (c) BVD Equivalent Circuit of Piezoelectric Systems under Electrical Excitation}

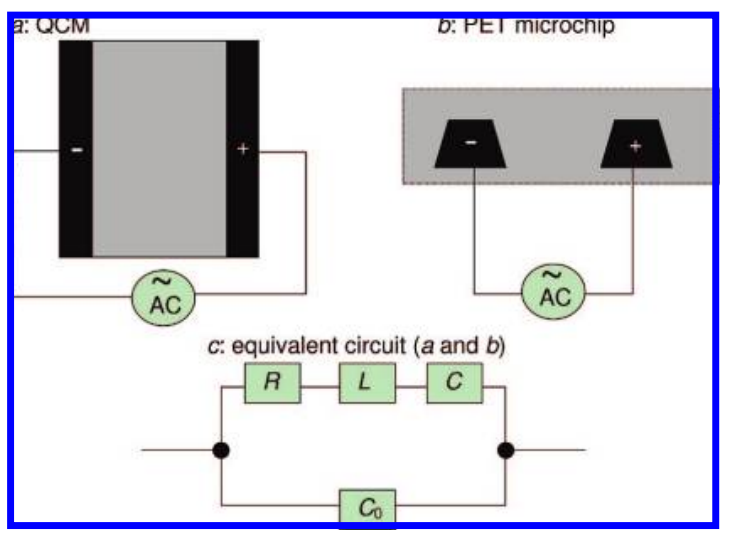

directly related to the physical properties of the resonator. The quality factors of both the QCM and PET microchip was calculated in order to compare rate of acoustic energy dissipation, as a lowquality factor can be detrimental to the accuracy of the gravimetric measurement: ${ }^{38}$

$$
Q=\frac{1}{R} \sqrt{\frac{L}{C}}
$$

The resonance of the PET microchip occurs in the same frequency range as the $\mathrm{QCM}$, but with a smaller quality factor (see Table 1). Some improvement of the geometry would be necessary to increase this quantity.

On the basis of this observation, the admittance spectra were recorded at 201 frequencies around $30 \mathrm{MHz}$ during successive cycles of DNA hybridization and showed reproducible changes on $R, L$, and $C$ parameters (Figure 5): the initial system consisted of an adsorbed 20-base DNA-thiol monolayer on the gold surface and the cell was filled with $196 \mu \mathrm{L}$ of $0.5 \mathrm{M} \mathrm{MgCl}_{2}$ solution. After a period of $50 \mathrm{~min}$, the resonance was stable and $4 \mu \mathrm{L}$ of a $1 \mathrm{mg}$ $\mathrm{mL}^{-1}$ DNA-target solution was introduced in the cell; the DNA concentration in the cell was then $20 \mu \mathrm{g} \mathrm{mL}^{-1}$. The evolution of the admittance at 201 frequencies around $30 \mathrm{MHz}$ was monitored before and after the addition of the DNA-target solution in the cell, and the data were analyzed in terms of BVD equivalent circuit. It was found that $(R, L)$ and $C$ varied in opposite directions with time during the DNA hybridization process (Figure 5). These responses were recorded at different times, before and after addition of a DNA solution in the device cell. This first approach was not perfectly adapted to observe DNA hybridization, as mentioned, but it is a preliminary and essential approach to investigate new electroacoustic devices. In a second development phase of this sensor, an appropriate algorithm, using a BVD model, will enable us to monitor in real time interfacial reaction, by calculating $R, L, C$, and frequency for each electroacoustic response. Then to obtain a simple sensor, an oscillator circuit will be developed.

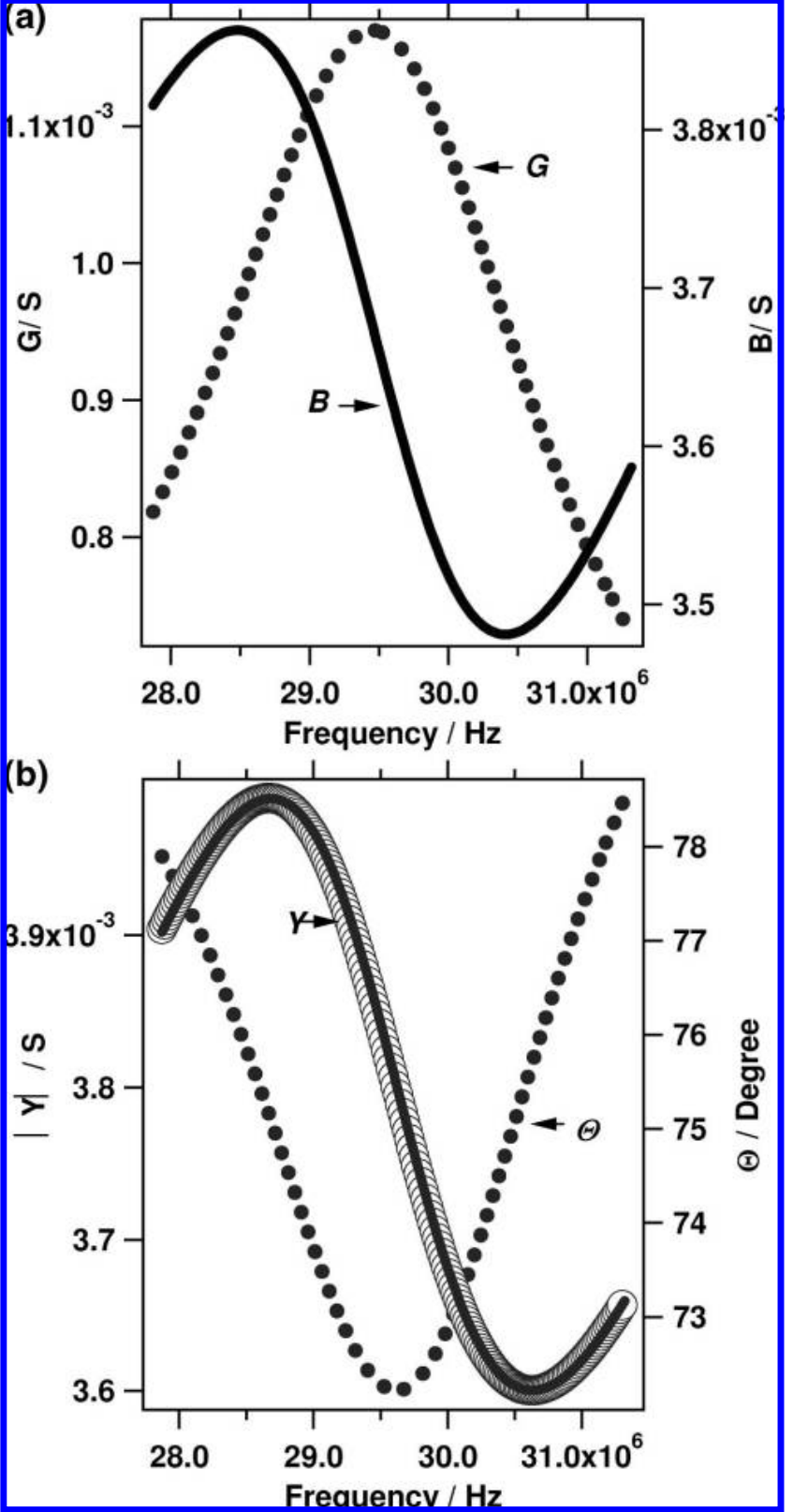

Figure 4. (a) Real $G$ and imaginary $B$ parts of the admittance versus frequency for a $\mathrm{MgCl}_{2}$ buffer-filled cell from immobilization of the 20base DNA thiol-labeled probe. (b) Bode representation: experimental admittance modulus (solid line), fitted admittance (open circles), and phase angle (dotted line).

\section{Table 1. PET Microchip Characteristics Compared to} QCM

\begin{tabular}{lccr} 
& $f_{0}(\mathrm{MHz})$ & $\Delta f(\mathrm{MHz})$ & $Q$ \\
PET & 29.6 & 3 & 10 \\
QCM & 27 & 0.02 & 1350 \\
\hline
\end{tabular}

\section{DIscussion}

To speculate about the possible origin of the resonances, the equations of piezoelectricity have been taken into account. The tensor equation of mechanical deformation $S$ under mechanical $T$ or electrical $E$ perturbation is given by

$$
T=C S-e E
$$




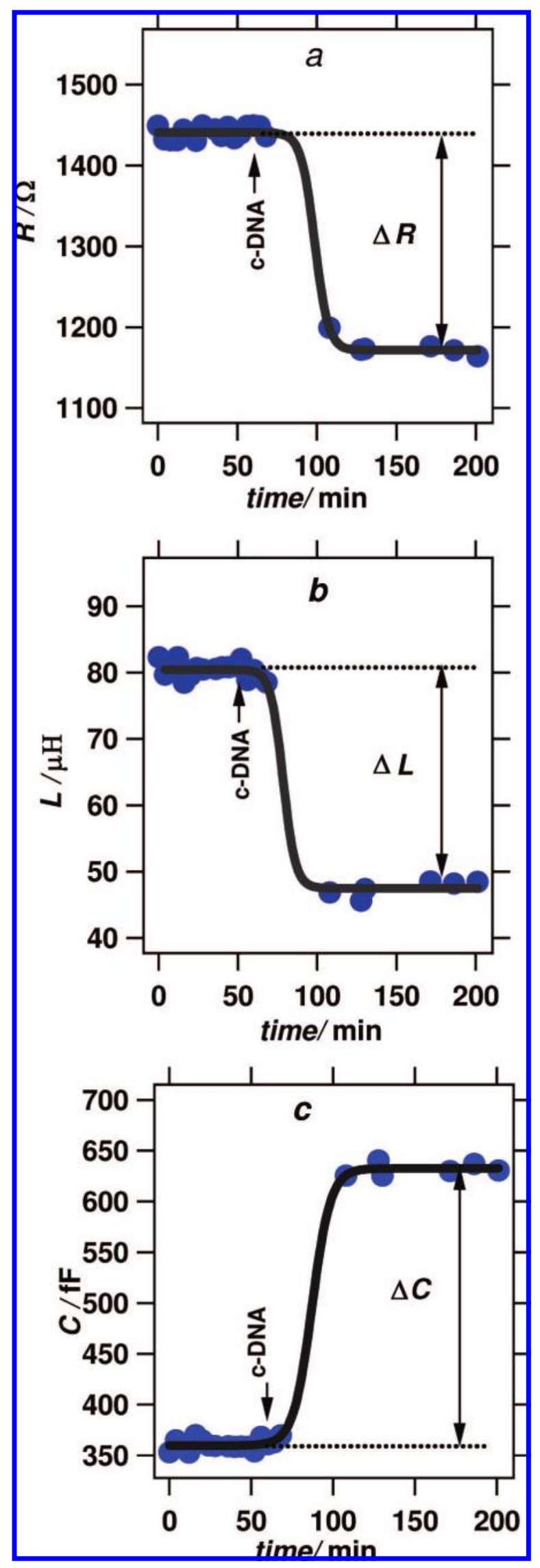

Figure 5. Sensor responses during cDNA (c-DNA) additions: (a) $R$ vs time. (b) $L$ vs time. (c) $C$ vs time. where $C$ is the elastic tensor of the material and $e$ the piezoelectric tensor. For the PET device, the perturbation is purely electric and so $T=0$. The mechanical deformation $C$ is given by the relation

$$
C S-e E=0
$$

The resolution of this equation yields resonance frequency:

$$
C_{i j}=4 \rho l^{2} f^{2}
$$

where $\rho$ is the material density, $l$ the propagation length, and $C_{i j}$ the coefficient of the elastic tensor: $C_{i j}$ depends on both material and wave propagation mode. Two important kinds of wave propagation modes have to be taken into account, (i) longitudinal and (ii) shear.

(i) In the case of a longitudinal mode,$^{39}$ the coefficient of the elastic tensor matrix to take into account is $C^{\star}$, which is equal to the Young modulus $E$ for a semicrystalline material. In these conditions, the relation between frequency and propagation length is given by

$$
E=4 \rho l^{2} f^{2}
$$

(ii) In the case of a shear mode, the coefficient of the elastic tensor to take into account is $C^{\star \star}$, which is equal for a semicrystalline material to

$$
C^{* *}=\frac{E}{2(1+v)}
$$

where $v$ is the Pascal viscosity adimensional coefficient. In these conditions, the relation between frequency and propagation length is given by

$$
\frac{E}{2(1+v)}=4 \rho l^{2} f^{2}
$$

Equations 9 and 11 permit us to calculate the propagation length of fundamental vibrations for, respectively, longitudinal (i) and (ii) shear modes, for each resonance, at 11.2 and $29.6 \mathrm{MHz}$. (PET Melinex: $\rho=1.410^{3} \mathrm{~kg} \mathrm{~m}^{-3}, E=5.3 \times 10^{9} \mathrm{~N} \mathrm{~m}^{-2}, v=$ $0.44)$. These calculated propagation lengths were compared to the geometric dimensions of the device, which are $86 \mu \mathrm{m}$ for the length between the electrodes and $40 \mu \mathrm{m}$ for the length between each electrode and the device surface. Results are given in the Table 2 .

There is a good agreement between path length calculated from resonance frequency considering a longitudinal propagation mode and the device dimensions. Moreover, the two resonances at 11.2 and $22.4 \mathrm{MHz}$ were hardly affected during filling of the cell with water, but the resonance at $29.6 \mathrm{MHz}$ was subject to significant changes. This last observation is in agreement with the analysis done, as the modification of the gold interface with

(38) (a) Rodriguez-Pardo, L.; Farina, J.; Gabrielli, C.; Perrot, H.; Brendel, R. Sens. Actuators, B 2004, 103, 318. (b) Rodriguez-Pardo, L.; Farina, J.; Gabrielli, C.; Perrot, H.; Brendel, R. IEEE Sens. J. 2005, 5, 1251.

(39) Kardasheva, B. K.; Nikanorova, S. P.; Kravchenkob, V. S.; Malinovb, V. I.; Punin, V. T. Tech. Phys. 2007, 52, 1519-1522. 
Table 2. Comparison between the Theoretical

Propagation Lengths with the Device Dimension

\begin{tabular}{cccc} 
& \multicolumn{2}{c}{ path length $l(\mu \mathrm{m})$} & \\
\cline { 2 - 3 }$f(\mathrm{MHz})$ & (i) longitudinal & (ii) shear & device dimensions $(\mu \mathrm{m})$ \\
11.2 & 87 & 51 & 86 \\
29.6 & 33 & 19 & 40 \\
\hline
\end{tabular}

exterior media has an influence on the resonance phenomenon that involves the surface, i.e., at $29.6 \mathrm{MHz}$. The initial hypothesis that the feeble piezoelectric character of the material is responsible for the observed resonance is consistent with the measured frequency and this last observation. In conclusion, the resonance at $11.2 \mathrm{MHz}$ can be attributed to the longitudinal vibration mode in the PET section localized between the two microelectrodes and the resonance at $29.6 \mathrm{MHz}$ to a longitudinal vibration mode in the PET section localized between the microelectrodes and the gold surface.

\section{CONCLUSION}

This work describes the development of a flexible electroacoustic PET microchip for bioanalysis. It was demonstrated in the first part that the $30-\mathrm{MHz}$ frequency resonance observed in the microchip results from the propagation of a mechanical longitu- dinal wave through the microelectrode/PET/gold layer interface. The feeble piezoelectric character discovered in this PET configuration is probably due to laser treatment, thereby affecting the property of the polymer. In a second part, the device was used to probe DNA hybridization by monitoring the $R L C$ parameter of a BVD resonant model. This first prototype, close to 100 times smaller than a quartz microbalance, is working in a contactless configuration well adapted to avoid faradic reaction that may damage biolayers. It is promising for integration of electroacoustic sensors toward biochips as schemes of QCM miniaturization were technologically limited because microsized mineral crystals are extremely brittle.

\section{ACKNOWLEDGMENT}

We thank Philippe Rousseau (CNRS-LISE) for fruitful discussions on this work, Valérie Devaud (LEPA, EPFL) for his technical help, Chantal Compère and Elisabeth Antoine (IFREMER Brest) for helpful discussion about DNA aspects, and ANR PRECODD for its financial support through the HAB-SEACHIP project.

Received for review March 3, 2008. Accepted October 2, 2008.

AC800443U 